\title{
Iron-based subsurface arsenic removal by aeration (SAR) - results of a pilot-scale plant in Vietnam
}

\author{
V.T. Luong ${ }^{1}$, E.E. Cañas Kurz ${ }^{2,3}$, U. Hellriegel ${ }^{2}$, L.L. Tran ${ }^{3}$, J. Hoinkis ${ }^{2}$ \& J. Bundschuh ${ }^{1}$ \\ ${ }^{1}$ Faculty of Health, Engineering and Sciences, University of Southern Queensland, Toowoomba, QLD, Australia \\ ${ }^{2}$ Department of Mechatronics and Sensor Systems Technology, Vietnamese-German University, \\ Binh Duong Province, Vietnam \\ ${ }^{3}$ Center of Applied Research, Karlsruhe University of Applied Sciences, Karlsruhe, Germany
}

\begin{abstract}
Arsenic contamination in groundwater is a critical issue and one that causes great concern around the world with many negative health impacts on the human body. In-situ subsurface arsenic immobilization by aeration has shown to be a promising, convenient technology with high treatment efficiency. In contrast to most of other As-remediation technologies, in-situ subsurface immobilization offers the advantage of negligible waste production and hence has the potential of being a long-term, sustainable treatment option. A pilot scale plant (capacity $=2 \mathrm{~m}^{3} \mathrm{~d}^{-1}$ ) for the subsurface arsenic removal (SAR) was tested in the Mekong Delta region in South Vietnam. Within the first two weeks of operation the initial concentrations of $81 \pm 14 \mu \mathrm{g} \mathrm{As} \mathrm{L}^{-1}$ were successfully lowered to below the guideline value limit for drinking water recommended by the WHO of $10 \mu \mathrm{g} \mathrm{L}^{-1}$. Results indicated adsorption and co-precipitation with iron oxides as the principal mechanism responsible for the arsenic removal. Evaluation of the results demonstrates the feasibility of in-situ technology for arsenic mitigation. However, difficulties in manganese removal arose due to existing high ammonia concentrations and natural occurring geochemical reducing conditions.
\end{abstract}

\section{INTRODUCTION}

Arsenic (As) is considered to be one of the most serious inorganic contaminants in groundwater and it is recognized as a significant environmental cause of cancer mortality globally (Martinez et al., 2011).

There are many established methods to treat arsenic laden water including precipitation, membrane technologies, adsorption, ion exchange and capacitive deionization which show many different advantages and disadvantages (Nicomel et al., 2015). The main disadvantage of - ex-situ - technologies is the generation of arsenic-laden waste which has to be either regenerated or disposed safely (Clancy et al., 2013).

As questions regarding the efforts, safety and costs for the disposal of arsenic waste arise, alternative techniques with a sustainable approach are needed. The in-situ arsenic remediation by aeration is a technique based on the subsurface iron removal (SIR), which has proven for many years as a technically feasible technique in a variety of hydrogeochemical settings (Rott \& Kauffmann, 2008). However, subsurface arsenic removal (SAR) is not yet an established solution since it shows vulnerability to diverse geochemical conditions such as $\mathrm{pH}, \mathrm{Fe}$ :As ratio, and the presence of co-ions making it sometimes difficult to comply with the stringent guideline value for drinking water of $10 \mu \mathrm{g} \mathrm{L}^{-1}$ (WHO, 2011). However, the salient advantage relies on its low operating and maintenance costs, and its negligible waste production, as arsenic is bound to the subsurface matrix (Rott \& Kauffmann, 2008).

This study shows the results of a SAR pilot plant installed for the in-situ treatment of As contaminated groundwater in the An Giang Province, Vietnam.

\section{METHODS}

\subsection{Subsurface arsenic removal plant}

The subsurface arsenic removal bases on the adsorption and co-precipitation of arsenic onto iron(hydr)oxides. The operation of the SAR plant took place in the three following steps: 1. Aeration: groundwater is extracted and aerated; 2. Infiltration: oxygenrich water is re-injected into the aquifer through the infiltration well inducing the formation of oxidation and adsorption zones around the tubewell; 3. Adsorption: arsenic adsorbs onto the formed iron-oxides and co-precipitates in the oxide-matrix. Treated water can be extracted from the well.

The SAR pilot plant consists of an air-injection nozzle for aeration, a storage tank (390 L) and the delivery pump with pressure vessel. This study shows the results of the first five months of operation, including commissioning and installation of an extra tank $(1000 \mathrm{~L})$ after three months operation for increased 


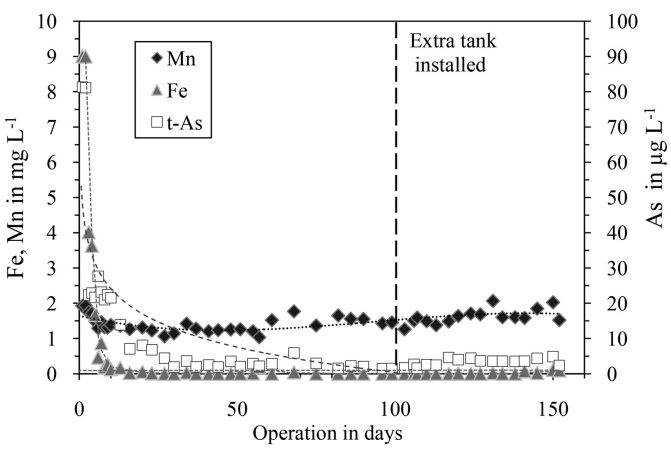

Figure 1. Iron, manganese (left axis) and total arsenic concentration (right axis) of treated groundwater.

infiltration volume $\left(\mathrm{V}_{\text {total }}=1390 \mathrm{~L}\right)$. The aeration and infiltration cycles (max. 2 cycles per day) were regulated by a consumption-based controller. With an infiltration carried out twice a day, a total max. Volume $\mathrm{V}_{\text {treated }}=1,900 \mathrm{~L}$ could be extracted daily.

\section{RESULTS AND DISCUSSION}

\subsection{Iron and arsenic removal}

The initial concentrations of iron $8.2 \pm 1 \mathrm{mg} \mathrm{Fe} \mathrm{L}^{-1}$ were lowered to below Vietnamese drinking water standard value of $0.3 \mathrm{mg} \mathrm{Fe} \mathrm{L}^{-1}$ within the first week of operation. Compliance for arsenic standard of $10 \mu \mathrm{g}$ As $\mathrm{L}^{-1}$ was achieved after 10 days.

The results demonstrate that the oxidation of dissolved $\mathrm{Fe}^{2+}$ to particulate $\mathrm{Fe}^{3+}$ occurs rapidly after the first infiltration of oxygen into the aquifer, as shown in Figure 1. The mitigation of arsenic is directly proportional to the oxidation of iron, thus validating the proposed adsorption mechanisms of arsenic onto iron(hydr)oxides.

\subsection{Manganese and ammonium}

Achieving manganese drinking standard $(0.3 \mathrm{mg}$ $\mathrm{MnL}^{-1}$ ) was not accomplished within the first 5 months of operation. The small changes on manganese concentrations shown in Fig. 1 (average $1.5 \pm 0.2 \mathrm{mg} \mathrm{MnL}^{-1}$ ) can be associated to natural hydrological fluctuations. The limitations on $\mathrm{Mn}$ removal might be related to the rather absent microbial activity and unfavorable natural low redox potential which makes the - already slow Mn oxidation challenging. However, long-time experience with SIR shows that a complete Mn removal can take up to 6 months, so that mitigation of Mn with SAR is not to be excluded (Grischek et al., 2015).
High initial ammonium concentrations $(1.1 \pm$ $0.1 \mathrm{mg} \mathrm{NH} \mathrm{N}^{+} \mathrm{L}^{-1}$ ) can also be associated to the poor Mn mitigation, as the oxidation of $\mathrm{NH}_{4}^{+}$is highly oxygen consuming and the oxidation of $\mathrm{Mn}^{2+}$ can take place only after $\mathrm{NH}_{4}^{+}$has been fully oxidized. Further monitoring of $\mathrm{Mn}$ concentrations is required to assess feasibility for Mn mitigation under the different conditions in Vietnam.

In order to achieve Mn standard for drinking purpose, a downstream treatment such as greensand filters $\left(\mathrm{MnO}_{2}\right)$ might be a viable low-cost option.

\section{CONCLUSIONS}

Results show that subsurface arsenic removal (SAR) is a feasible technique for achieving drinking water standard of $10 \mu \mathrm{g} \mathrm{As} \mathrm{L}^{-1}$, also for low-income countries such as Vietnam. The salient advantage of this technique is the negligible waste production. Hydrogeochemical conditions may affect the efficiency for achieving drinking water standard when high $\mathrm{NH}_{4}^{+}$and Mn concentrations are present.

\section{ACKNOWLEDGEMENTS}

The project was funded by the German Federal Ministry of Education and Research (BMBF) under the grant number 02WAV1413A.

\section{REFERENCES}

Clancy, T.M., Hayes, K.F. \& Raskin, L. 2013. Arsenic waste management. a critical review of testing and disposal of arsenic-bearing solid wastes generated during arsenic removal from drinking water. Environ. Sci. and Technol. 47(19): 10799-10812.

Grischek, T., Winkelnkemper, T., Ebermann, J. \& Herlitzius, J. 2015. Small scale subsurface iron removal in Germany: 5th GEOINDO 2015, Khon Kaen, Thailand.

Martinez, V.D., Vucic, E.A., Becker-Santos, D.D., Gil, L. \& Lam, W.L. 2011. Arsenic exposure and the induction of human cancers. J. Toxicol. 2011: 1-13.

Nicomel, N.R., Leus, K., Folens, K., van der Voort, P. \& Du Laing, G. 2015. Technologies for arsenic removal from water: current status and future perspectives. Int. J. Environ. Res. Public Health 13(1): 62.

Rott, U. \& Kauffmann, H. 2008. A contribution to solve the arsenic problem in groundwater of Ganges Delta by in-situ treatment. Wat. Sci. Tech. 58(10): 2009-2015.

WHO, 2011. Guidelines for drinking-water quality. World Health Organization, Geneva. 